This is the final peer-reviewed accepted manuscript of:

Vignali, V., Cuppi, F., Acerra, E., Bichicchi, A., Lantieri, C., Simone, A., \& Costa, M. (2019). Effects of median refuge island and flashing vertical sign on conspicuity and safety of unsignalized crosswalks. Transportation Research Part F: Traffic Psychology and Behaviour, 60, 427-439.

The final published version is available online at:

https://doi.org/10.1016/i.trf.2018.10.033

Rights / License:

The terms and conditions for the reuse of this version of the manuscript are specified in the publishing policy. For all terms of use and more information see the publisher's website.

This item was downloaded from IRIS Università di Bologna (https://cris.unibo.it/)

When citing, please refer to the published version. 


\title{
Effects of median refuge island and flashing vertical sign on conspicuity and safety of unsignalized crosswalks
}

\author{
Valeria Vignali a $\Uparrow$, Federico Cuppi a, Ennia Acerra ${ }^{a}$, Arianna Bichicchi ${ }^{\text {a }}$, Claudio Lantieri a \\ Andrea Simone ${ }^{a}$, Marco Costa ${ }^{b}$ \\ ${ }^{a}$ Department of Civil, Chemical, Environmental and Material Engineering, University of Bologna, Italy ${ }^{b}$ \\ Department of Psychology, University of Bologna, Italy
}

\begin{abstract}
Pedestrian crossings are critical points in terms of road safety because they tend to be characterized by high accident rates. Pedestrian safety at zebra crossings depends mainly on vehicles speed.

In this study the effects of median refuge island and "Yield here to pedestrians" flashing vertical sign on pedestrian crossing conspicuity were assessed with a beforeafter analysis of both speed and visual behaviour of drivers approaching to crosswalks. The elements of the pedestrian crossing that were more salient and how drivers' visual behaviour was related to speed were assessed analysing drivers' eye movements. The intervention significantly increased the fixation time to the zebra markings and the addition of the flashing light increased conspicuity and fixation time to the vertical sign. The median refuge island was glanced by $60.7 \%$ of the drivers. Distance of first-fixation of the crosswalk increased by $44.7 \%$. Notwithstanding mean and V85 speed parameters were lower after the intervention, the effects on crosswalk visual attention were higher than on speed.
\end{abstract}

\author{
Keywords: \\ Eye tracking \\ Pedestrians \\ Driver behaviour \\ Unsignalized crosswalk \\ Zebra crossing \\ Median refuge island \\ Urban road \\ Flashing vertical pedestrian sign \\ Conspicuity \\ Road safety
}

\section{Introduction}

\subsection{Safety issues for pedestrians at crosswalks}

Traffic safety depends upon the integrated and complex relationship between various components: driver psychology, traffic, vehicle, environment and road infrastructure (Dondi, Simone, Lantieri, \& Vignali, 2011). According to statistics, the behavioural component is the most important factor in traffic safety, being responsible for most accidents (Bucchi, Sangiorgi, \& Vignali, 2012; Colonna et al., 2018).

When considering the interaction between drivers and road infrastructure, pedestrian crossings play a significant role, because they are critical points in terms of safety. Unprotected by a vehicle structure, safety belt or helmet, pedestrians are especially exposed to the risk of serious injuries and have a smaller chance of surviving after an accident (Kim, Made Brunner, Yamashita, \& Prevention, 2012; Olszewski, Szagała, Wolanski, \& Zielinska, 2015).

Pedestrian accidents mainly occur on urban roads, because of the greater population and driver density and the longer average distances walked by residents in urban areas in comparison with rural roads (Damsere-Derry, Ebel, B.E., Mock, C. M., Afukaar, Donkor, \& Prevention, 2010; Guo, Wang, Guo, Jiang, \& Bubb, 2012; Zeeger and Bushell, 2012). In rural areas, in fact, longer distances of travel, higher vehicle speed and higher proportion of heavy goods traffic, compared to urban environments, make walking trips less frequent. Urban areas have more pedestrians than high-speed roads, which leads to a greater number of interactions between vehicles and pedestrians, increasing the risk of accidents (Antov, Rõivas, Pashkevich, \& Ernits, 2013; Hamed, 2001; Sisopiku \& Akin, 2003).

Unsurprisingly, pedestrians are more likely to be seriously injured while crossing the road. At crosswalks, in fact, pedestrians reduce their level of attention believing that crossing would be intrinsically safe, also if they cannot predict or control the actions of approaching drivers (Sisopiku \& Akin, 2003). The negligence or inattentiveness of a car or motorcycle driver is the mayor cause of most pedestrian accidents. Driver's inattentiveness could result from talking on cell phones, eating while driving, programming a GPS, applying make-up or a variety of other activities (Antov et al., 2013; Hamed, 2001). 
To solve this problem, extensive researches have been conducted to evaluate the safety countermeasures for increasing pedestrian safety at urban crosswalks. They generally agree that pedestrian-vehicle crashes are associated with a lack of driver's compliance and that pedestrian safety at zebra crossings depends mainly on the vehicle speed. With an increase in speed, in fact, the probability of a vehicle-pedestrian conflict and of a pedestrian fatality accident is higher (Guo, Liu, Liang, \& Wang, 2016; Hakkert, Gitelman, \& Ben-Shabat, 2002; Haleem, Alluri, Gan, \& Prevention, 2015; Kröyer, H.R.G., Jonsson, Várhelyi, \& Prevention, 2014; Pasanen, 1992; Rosén \& Sander, 2009; Rosén, Stigson, Sander, \& Prevention, 2011; Tefft, 2013; Várhelyi, 1998; Zeeger \& Bushell, 2012).

To reduce drivers' speed, different approaches can be followed: modification of the road environment, enforcement of traffic safety laws, optimization of vehicle design and pedestrian education. Modification of the vehicle design to reduce the severity of injuries to pedestrians is a main focus in Europe, but it is a long-term safety measure. Pedestrian education is a popular approach but, with the exception of children, there is a lack of evidence about its efficacy (Duperrex, Bunn, \& Roberts, 2002; O’Neill et al., 2002). Modification of the road environment is a widely used approach that has proven to be highly effective (Retting, Fergusson, \& McCartt, 2003).

A number of road safety countermeasures aimed at modifying the driver's speed behavior while approaching unsignalized pedestrian crossings have been evaluated with positive results. However, their effectiveness is generally provided by specific parameters, as the operating speed reduction or the distance at which the drivers yields to pedestrians (Bella \& Silvestri, 2015).

However, such results do not allow a complete analysis of the effectiveness of the safety measures, because they do not consider the drivers' behaviour in terms of detection and perception of the crosswalk elements. The assessment of crosswalk conspicuity is very important because it is directly related to the drivers' attention level and hazard anticipation (Horswill \& McKenna, 2004; Klauer, Dingus, Neale, Sudweeks, \& Ramsey, 2006; Taylor et al., 2013). Eye-movement recording is currently one of the best method that allows an objective quantitative assessment of conspicuity (Costa, Bonetti, Bellelli, Lantieri, Vignali, \& Simone, 2017; Kapitaniak, Walczak, Kosobudzki, Józ' wiak, \& Bortkiewicz, 2015; Taylor et al., 2013; Topolsek et al., 2016).

\subsection{Countermeasures to improve pedestrian safety at unsignalized crosswalks}

Several countermeasures aimed at modifying the drivers' speed behavior while approaching unsignalized pedestrian crossings on collector roads have been investigated in the literature (Bella \& Silvestri, 2015; Fitzpatrick et al., 2006; Hakkert et al., 2002; Pulu gurtha, Krishnakumar, Nambisan, 2007; Zeeger \& Bushell, 2012). The most used driver-oriented countermeasures are:

(a) median refuge island, to make the street crossing easier and more convenient;

(b) advanced yield lines, to improve the visibility of the pedestrians crossing;

(c) removal of parking, to clear the line of sight to approaching vehicles;

(d) installation of curb extensions, to improve visibility;

(e) installation of pedestrian vertical signs, to warn motorists of crossing pedestrians;(f) installation of in-pavement warning lights, to alert drivers of the crosswalk.

In a complex street environment, like collector roads, it is difficult to have a significant speed reduction with a single treatment. It is usually required a combination of several different countermeasures intended to serve different purposes.

Median refuge island slows traffic because it narrows the road eliminating long and wide straight sections, and it reminds drivers that pedestrians could be crossing the road. Furthermore, it provides a useful refuge area to pedestrians that can stop in the island, and can split the crossing into two stages for each traffic direction. They are largely self-explaining and have the ability to create the visual impression that the road is not intended for fast through-movement of traffic (Leden, Gårder, \& Johansson, 2006; Martin, 2006; Sanca, 2002). Several experiences showed their effectiveness in terms of operating speed reduction of the vehicles (Fildes, Fletcher, \& Corrigan, 1987; Kolsrud, 1985; Vey \& Ferreri, 1968; Yagar $\&$ Van Aerde, 1983). Elvik and Vaa (2004) estimated that median refuge island reduces the number of pedestrian injury crashes by about $18 \%$. For unsignalized pedestrian crossings, Zeeger and Bushell (2012) found that fatal pedestrian crash risk increased when the median refuge island was lacking.

Advanced yield markings consist of a series of triangular pavement markings that are placed across the travel lane between 6 and $15 \mathrm{~m}$ in advance of the zebra crossing. A "Yield here to pedestrians" vertical sign is also placed at the markings location. This countermeasure is aimed at improving the yielding compliance, alerting the driver further upstream of the crosswalk of the possible presence of pedestrians and prompting the driver to yield. Several studies have shown the effectiveness of this treatment because it increased the distance at which the driver yields to pedestrians, reducing the number of conflicts and increasing the number of drivers that yield (Bella \& Silvestri, 2015; Samuel et al., 2013; Van Houten, Malenfant, \& McCusker, 2001, 2002).

Parking removal is designed to not allow parking upstream of the zebra crossing, improving pedestrian visibility. The presence of on-street parking, in fact, is associated with an increased risk of accident. A model for the prediction of accidents showed that the contribution of the presence of parking on the roadside increased the accident levels more than road width (Greibe, 2003). Edquist, Rudin-Brown, Lenné, and Prevention (2012) found that the effect of the presence of on-street parking was statistically significantly for several variables, such as the time to brake, time to accelerator release, minimum time to collision, and number of collisions. Bella and Silvestri (2015) confirmed that, with parking restrictions, the driver had better sight of the zebra crossing and could clearly see if the pedestrian is present or not, reaching the minimum speed level farther from the zebra crossing.

Curb extension is an extension of the edge of the sidewalk and is commonly made along roads that are equipped with parking places on the lane side. The curb extends up to the line that separates the lane from parking stalls on the side of the roadway. The effects that are expected from this safety countermeasure are to slow down the approaching vehicles, reducing the pedestrian exposure and increasing pedestrian visibility. Several experiences showed their effectiveness in terms of both vehicle operating speed reduction (Hawley, Henson, Hulse, \& Brindle, 1992; Huang \& Cynecki, 2001; Macbeth, 1995; Replogle, 1992) and increment in the number of drivers that yielded to pedestrians (Randal, 2005). Bella and 
Silvestri (2015) confirmed that curb extension was a countermeasure that induced appropriate driver's speed behaviour, while approaching the zebra crossing. More than $80 \%$ of the driver sample perceived that curb extension was effective, which indicated that when this countermeasure was present, the drivers were more willing to yield and that the visibility of the pedestrian was increased.

Pedestrian vertical signs ("Yield here to pedestrians" sign) are mounted on poles on the crosswalk right side or on cantilever support arms over the traffic lanes, in order to warn motorists of crossing pedestrians (Beeber, 2011). To improve their visibility, LED flashers can be mounted, with an irregular flash pattern to warn motorists of the crosswalk. Several experiences showed their effectiveness in terms of operating speed reduction of the vehicle. Sherbutt, Van Houten, Turner, and Huitema (2009) conducted three experiments on the effects of flashing pedestrian vertical signs on motorists' yielding behavior at uncontrolled marked crosswalks. The results showed that the addition of the flashing light could produce a large increase in yielding behavior. Motorist yielding at baseline was $18.2 \%$. Upon installation of the flashing lights on the vertical sign, yielding increased to $81.2 \%$. A previous study by Van Houten, Ellis, and Marmolejo (2008) also showed that LED flashers installed on pedestrian signs produced a marked increase in yielding behavior. In addition, the data indicated that the use of the device produced a reduction in evasive maneuvers between drivers and pedestrians, and a reduction in the percentage of pedestrians trapped in the crosswalk at the center of the road without a median island.

An in-pavement warning lights system consists of lights embedded in the pavement along both sides of the crosswalk. When a pedestrian activates the lights, they flash at a constant rate alerting the driver that a pedestrian is present and therefore the driver should stop to allow the pedestrian to cross. The lights are only activated by a pedestrian and they shut off after a predetermined amount of time. The intent of in-pavement lights is to provide a better warning to drivers that a pedestrian is present in the proximity of a crosswalk, and are especially valuable at night when the lights are most visible.

Several studies have shown the effectiveness of this treatment in terms of operating speed reduction (Hakkert, Gitelman, \& Ben-Shabat, 2001) and of percentage of drivers who yielded (Gadiel, 2014; Kannel \& Jansen, 2004; Malek, 2001; Rousseau, Tucker, \& Do, 2004).

In this study we investigated the combination of a median refuge island and the installation of a "Yield here to pedestrians" flashing vertical sign. This intervention on collector roads is characterized by low cost, simple installation and we suggested that it could be of high potential effectiveness on driver behaviour.

\subsection{Drivers' eye-movements approaching pedestrian crossings}

The main applications of mobile eye tracking studies in driving behaviour are steering, braking, multitasking, city driving and driving learning (Land \& Tatler, 2009). In addition, eye tracking was also used to study drivers' detection, perception and acknowledgment of different road elements, to optimize the driving strategy and prevent accidents (Bongiorno, Bosurgi, Pellegrino, \& Sollazzo, 2017; Costa, Simone, Vignali, Lantieri, Bucchi, \& Dondi, 2014; Costa, Bonetti, Vignali, Lantieri, \& Simone, 2018; Costa, Simone, Vignali, Lantieri, \& Palena, 2018; Inman, 2012; Kapitaniak et al., 2015; Lantieri et al., 2015; Mantuano, Bernardi, \& Rupi, 2017).

The need to include eye-movement recording in this evaluation arose from the fact that vision is the predominant sensory modality used when driving (Crundall \& Underwood, 2011). Understanding driver's vision helps to better explain safe or unsafe driving behaviour on roads.

Recording and analysing eye movements provide important elements for understanding the nature of the task of vehicle driving. These results make it possible to optimize driver training strategy and prevent accidents, because errors in visual attention are responsible for a large proportion of traffic accident (Chapman \& Underwood, 1989; Kapitaniak et al., 2015). Whereas researchers have analysed the visual perception of car drivers in many eye-tracking experiments, there are only few studies that applied this methodology to investigatedriver-pedestrian interaction (Trefzger, Blascheck, Raschke, Hausmann, \& Schlegel, 2018).

Moreover, most of these last studies used the eye-tracking apparatus to investigate pedestrian behaviour, recording visual fixations and gaze performances, without considering car drivers (Biassoni, Confalonieri, \& Ciceri, 2018; Bock, Brustio, \& Borisova, 2015; Davoudian \& Raynham, 2012; Fotios, Uttley, \& Hara, 2013; Trefzger et al., 2018; Zito et al., 2015).

Ciceri, Ruscio, Confalonieri, Vangi, and Virga (2013) examined driver's behaviour when approaching to crosswalks. Some driving scenarios were simulated, manipulating the presence/absence of zebra crossing, pedestrian road signs and the pedestrian position. Drivers' fixation time and the time to first fixation, which was the time it took for the driver to shift his/her gaze towards the moving pedestrian, were evaluated. The more complex the scene in terms of road signs and expectability, the less the driver looked at the pedestrian before crossing, and the longer it took to be aware of the movement of the pedestrian.

Grüner et al. (2017) evaluated the influence of the road environment on the driver distraction when approaching a crosswalk. The results showed that the driver's expectation of careless pedestrians crossing the street could be reasonably higher in residential areas, where traffic was weaker compared to main roads. This has prompted the driver's adaptive monitoring of the roadsides when driving through residential areas. In fact, more eye movements were directed to the right roadside in this context.

Olson, Battle, and Aoki (1989) studied driver distraction when approaching to crosswalks, in a situation with a preceding car, and they found that drivers' fixations tended to be more focused on the preceding car, especially during night driving compared to daytime, ignoring pedestrians ahead on the road. Importantly, they did not instruct the drivers to follow the preceding car.

Dukic, Ahlstrom, Patten, Kettwich, and Kircher (2013) and Maxera, Kledus, and Semela (2015) investigated pedestrian detection using eye tracking and they found that during night driving, drivers spotted pedestrians at crosswalks relatively late. In such situations, increasing the conspicuity of pedestrians proved to be effective for enhancing their earlier detection. This is because, generally, drivers detected more salient objects earlier than less salient ones. The salience of objects depends on features of the object itself. For example, bigger or stronger illuminated objects appeared more salient and tended to attract more and longer fixations, compared to smaller and less illuminated objects as pedestrians.

Pomarjanschi, Dorr, and Barth (2012) explored the potential of gaze guidance in driving and analyzed eye movements and driving behavior in safety-critical situations. They collected eye movements from participants instructed to drive predetermined routes in a driving simulator. While driving, the participants performed various cognitive tasks designed to divert their attention away from the road. Potentially dangerous events, such 
as a pedestrian suddenly crossing the street, were highlighted with temporally transient gaze-contingent cues, which were triggered if the subject did not look at the pedestrian. Eye movements had a reduced variability after the gaze-capturing event and shorter reaction times to it. More importantly, gaze guidance leaded to a safer driving behavior and a significantly reduced number of collisions.

Fisher and Garay-Vega (2012) compared, on a simulator, drivers' performance (eye fixations and yielding behavior) at marked mid-block crosswalks in multi-threat scenarios when the crosswalks had advance yield markings and "Yield here to pedestrians" signs versus a control condition of crosswalks with standard markings. Advance yield markings and "Yield here to pedestrians" signs lead to changes in drivers' behavior in terms of reduction of pedestrian-vehicle conflicts and an increase of drivers' glances towards the pedestrian, an increase of the distance at which the pedestrian was first glanced, and an increase of the likelihood of yielding to the pedestrian.

Gómez et al. (2013), studying the driver's eye fixations and yielding behavior on a simulator, confirmed that with advance yield markings fewer crashes occurred and drivers looked much more frequently and much sooner to pedestrians.

The literature review showed that many eye-tracking research studies analyzed the drivers' pedestrian detection and only few focused the attention on the specific factors that improved the crosswalk conspicuity.

Moreover, these last studies mainly used eye-movement tracking in simulation studies that do not reflect the behaviour and situation of drivers and pedestrians in real traffic environments.

So, the main aim of this study was a before-after evaluation of a combined intervention on unsignalized crosswalks in a real road context, assessing both speed and eye-movements approaching a sequence of crosswalks before and after the intervention.

Six crosswalks were included and the intervention consisted in the introduction of a median refuge island and a "Yield here to pedestrians" flashing vertical sign. Driver's eye-movement recording allowed an assessment of which elements of the pedestrian crossing were more visually salient and how the driver's visual behaviour was related to speed.

A safe - effective crosswalk design, in fact, should alert drivers about the presence of a pedestrian crossing, maintaining their attention to the roadway, avoiding any source of potential distraction, and inducing a proper speed adaptation.

\section{Method}

\subsection{Participants}

Ten drivers were involved in the study, 7 males $\left(M_{\text {age }}=48.86\right.$ years, range: $\left.35-61, S D=9.77\right)$ and 3 females $\left(M_{\text {age }}=48.67\right.$ years, range: $41-53$, $\mathrm{SD}=6.66$ ). Participants had normal vision and none of them wore eyeglasses or lenses, to avoid artefacts in eye-movement monitoring. They were not paid and they were blind to the aims of the study. They were informed that the aim was to test the mobile eye-recording device while driving.

All participants had a Category-B driving license (for cars). Average driving experience was 32.86 years ( $\mathrm{SD}=9.17)$ for male drivers, and 32.67 years $(\mathrm{SD}=6.81)$ for female drivers. Mean kilometres per year were $19,714 \mathrm{~km}(\mathrm{SD}=9160)$ for male drivers and $16,667 \mathrm{~km}(\mathrm{SD}=2887)$ for female drivers.

None of the participants had previous driving experience on the road segment considered in this study.

\subsection{Crosswalks}

Six pedestrian crossings along the provincial route (Italy - SP3 "Del Rabbi”) were the focus of this study. The route was a single carriagewaytwo lanes road that is located in the north of Italy, in the Emilia Romagna region, between the town of Forli and the border of the Tuscany region, connecting small urban centers along a valley.

Specifically, we considered the part of the route that crossed San Lorenzo in Noceto for approximately $2.15 \mathrm{~km}$ (Fig. 1), with a rather homogeneous width of about $7.00 \mathrm{~m}$ (two $3.00 \mathrm{~m}$ wide lanes and one $1.00 \mathrm{~m}$ wide sidewalk).

The posted speed limit was $50 \mathrm{~km} / \mathrm{h}$. The average daily traffic along the examined road segment was about 6300 vehicles/day with a $5 \%$ of heavy vehicles.

This segment had the highest social costs for accidents in the Province of Forlì for the years 2016 and 2017. The main cause for the accidents was the drivers' missed perception of the transition between rural and urban areas. Crossing small urban centres, the SP3 "Del Rabbi" is used by pedestrians, cyclists, powered two wheelers and various types of vehicles with substantial differences in speed, mass and level of protection. This resulted in increased vulnerability and conflicts between the motor vehicle drivers and pedestrians.

Drivers entering the urban centre of San Lorenzo in Noceto tended to maintain high speed and did not slow down appropriately, causing numerous pedestrian-vehicle crashes at zebra crossings.

All the pedestrian crossings were located inside the urban area of San Lorenzo in Noceto. They were placed on straight sections, far away from intersections, at an average mutual distance of about $113 \mathrm{~m}$. They were not raised and they had black and white zebra markings and standard vertical pedestrian signs without led lights, without kerb ramps (Fig. 2).

According to the Italian Highway Code (Ministry of Infrastructures and Transports, 1992), the high-visibility crosswalks markings were 1.50 $\mathrm{m}$ long, $0.50 \mathrm{~m}$ wide and spaced $0.50 \mathrm{~m}$ from one another. In addition, two "Yield here to pedestrians" vertical signs, one for each side, were placed on the sidewalk of the road in proximity of the markings.

The intervention to increase crosswalk safety included these changes, as illustrated in Fig. 3: 


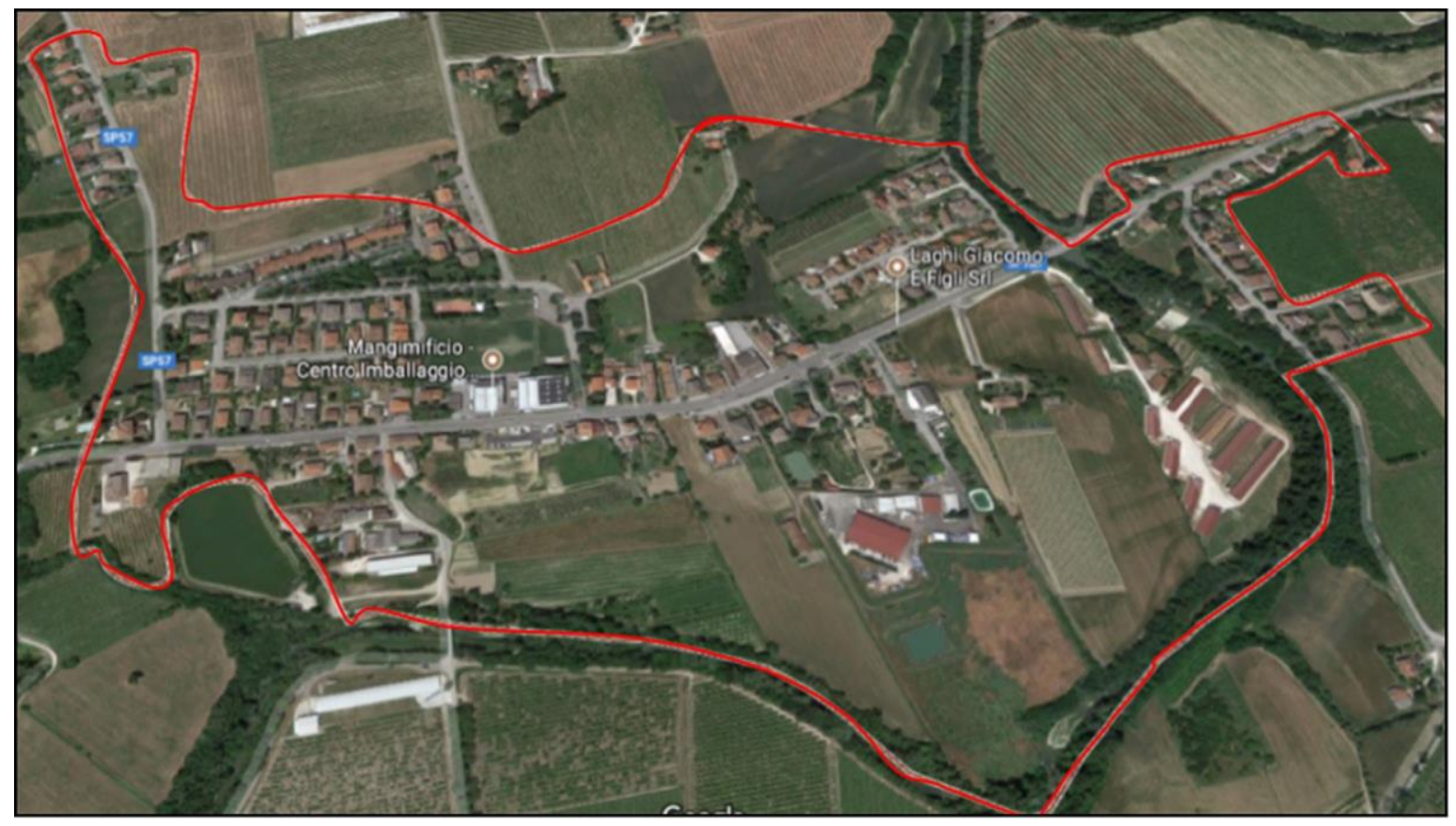

Fig. 1. Outline of the experimental route.

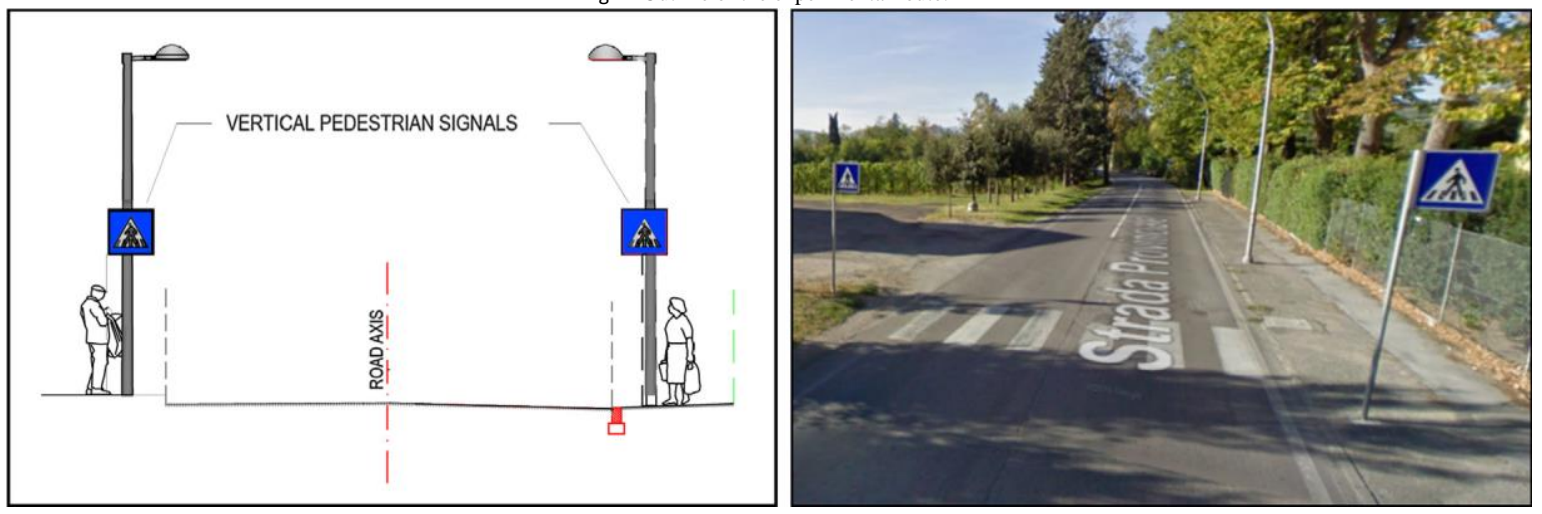

Fig. 2. Crosswalk design before the intervention.

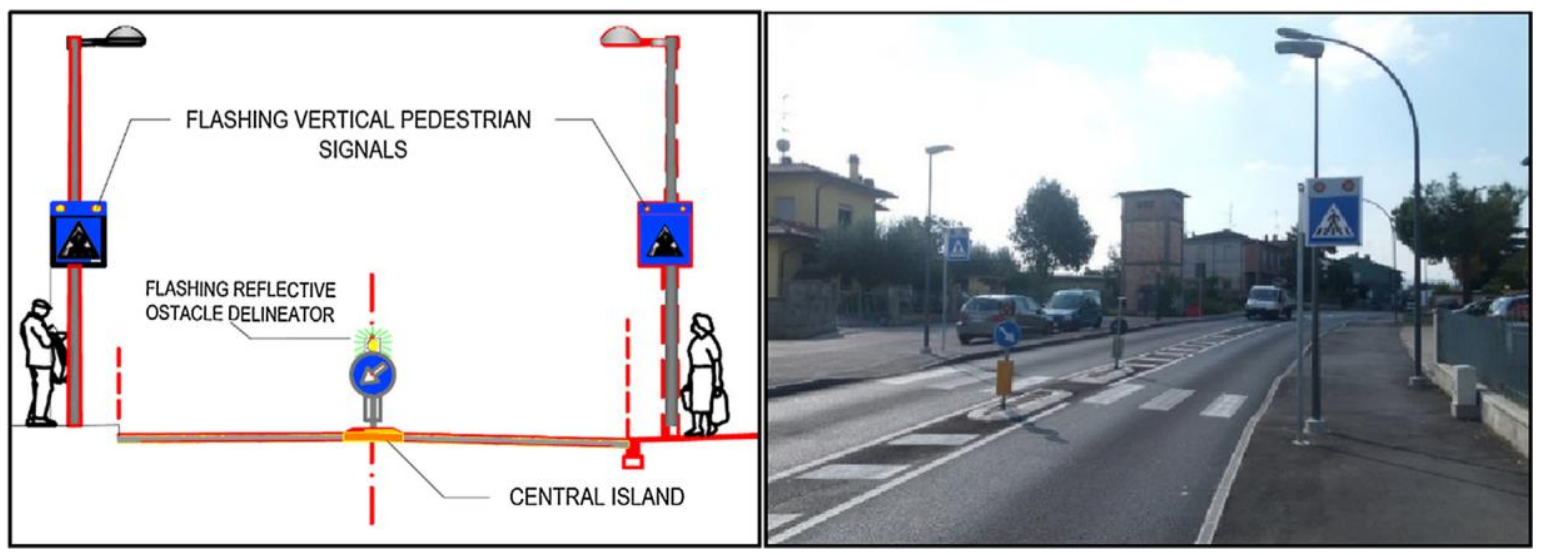

Fig. 3. Crosswalk design after the intervention. median refuge island, which allowed pedestrians to make a safer and easier two-stage crossing. According to the Italian Highway Code (Ministry of Infrastructures and Transports, 1992), the median refuge island, about $4 \mathrm{~m}$ long, was characterized by a continuous boundary marking, a curb, and it was separated from the traffic lanes by two 
shoulders with permanent white pavement marker. A yellow reflective obstacle delineator, coupled with the sign "passage allowed to the right" and a flashing LED lamp, was installed on the curb nose. The curb was $0.1 \mathrm{~m}$ high;

kerb ramps, for the mobility improvements of persons with motor disability, on each road side, with a slope of 8\%; "Yield here to pedestrians" signs, on the right side of the road, one per road side, with flashing LED lights; lateral LED lighting poles, one per side, placed on the external sidewalk, at $3.50 \mathrm{~m}$ height from the road level.

\subsection{Procedure and measurements}

A round trip of $7+7 \mathrm{~km}$ was driven by participants on the SP3 "Del Rabbi" before and after the intervention on the six crosswalks examined in this study. The participants had to drive following the SP3 "Del Rabbi" until instructions were given to return to the starting point along the same road. They did not have to plan the route.

Data collection was carried out from 9 to 12 a.m. to avoid peak hours, on two different days, with good metheorological condition. All the participants drove a Fiat Punto. The car was equipped with a Video Vbox Pro data recorder (Fig. 4). Two cameras and a GPS antenna were placed on the top of the car and connected to the Vbox data recorder, which recorded the driver's scene, with synchronized data on acceleration, speed and GPS coordinates. The system recorded velocity (accuracy: $0.1 \mathrm{~km} / \mathrm{h}$ ), acceleration (1\% accuracy), and distance with a $20 \mathrm{~Hz}$ sample rate.

Driver's eye movements were recorded using an ASL Mobile Eye-XG device (Fig. 4), consisting of two cameras attached to lightweight eyeglasses: the first camera recorded right eye movements, while the second recorded the visual scene. The eye camera, in particular, recorded the activity of the eye through a mirror capable of reflecting the infrared light, so as not to obscure the normal field of view of the subject. The sampling rate for the eye-movement recording was $30 \mathrm{~Hz}$ with an accuracy of $0.5-1$ (approximating the angular width of the fovea), as tested also in Costa et al. (2014). The ASL software was used

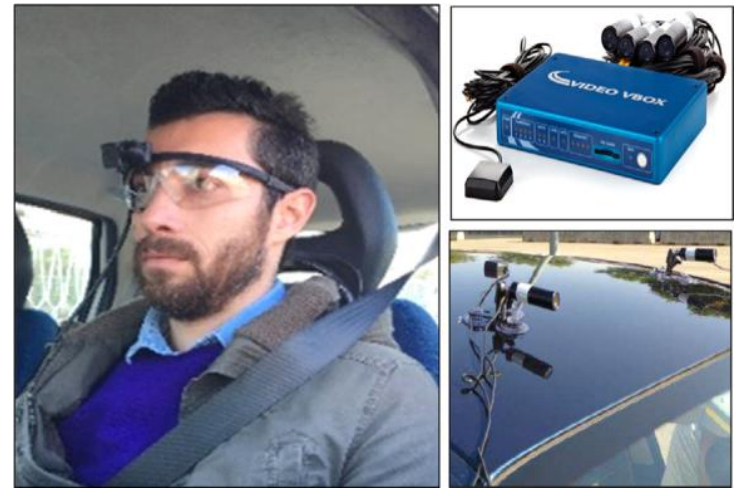

Fig. 4. Eye-tracking ASL Mobile Eye-XG and Video VBOX PRO data recorder.

to create a video for each participant, in which eye fixations were shown by a cross superimposed to the video of the driver's scene, allowing researchers to detect the sequence of specific points of the scene fixated by the participant.

A calibration procedure was carried out for each participant in order to get a good accuracy of the eye-movement recorder.

The ASL Mobile Eye-XG and the Video VBOX PRO equipments were kept in the back seat and were monitored by one of the investigators, who were asked not to talk to the driver with the exception of giving instructions about the direction and to give assistance in case of a specific request.

Each driver was given a two kilometer trial run to get used to the car before starting along the test route. After completing the driving session, participants were asked to fill in a questionnaire to gather the following information: age; class of driving licence; years of driving experience; kilometres covered per year; number of car crashes in which the participant had a direct responsibility.

\subsection{Data analysis}

The analysis of experimental data consisted of two parts: the analysis of speed data, acquired with the Video VBOX PRO data recorder, and the analysis of eye-movement data, obtained by the eye-tracking ASL Mobile Eye-XG. The same analyses were applied for the data acquired before and after the safety intervention on crosswalks. Since the experimental route was a round trip, each of the six crosswalks was crossed twice. In all the analysis we considered the average between the two directions for each crosswalk.

\subsubsection{Speed analysis}

For each participant, the Video Vbox-Pro output video was analyzed in order to assess operating speed, both before and after the crosswalks upgrading (before-after speed analysis). For each participant we considered the average speed and V85 (85th percentile speed) in two positions: (a) at the time of first-fixation to the crosswalk; (b) at the time the driver entered the crosswalk.

The before-after operating speed comparison is a very common method to evaluate the effectiveness of a road modification (World Road Association, 2003). 


\subsubsection{Number of fixations and fixation duration}

For each participant, the ASL Mobile Eye-XG video was analyzed frame-by-frame to assess the target of each participant's fixation. The targets under scrutiny were the "Yield here to pedestrians" vertical sign with flashing lights, the zebra crossing and the median refuge island (only in the after-intervention condition).

For each target we also computed the number of fixations. Fixation duration was computed multiplying by 33 ms the number of frames in which a target element of the pedestrian crossing was fixated.

To avoid the inclusion of saccadic movements, a target of the crosswalk was considered as fixated if the fixation point, defined by the intersection area of the cross shown in Fig. 5, was positioned on an element of the crosswalk for a minimum duration of two frames (66 ms).

The threshold of $66 \mathrm{~ms}$, which is low in comparison to a common filtering of $100 \mathrm{~ms}$ or higher usually found in eyetracking studies (Holmqvist et al., 2015), was dictated by the specific setting of this study that involved the recording of eye movements while driving. Velichkovsky, Domhoefer, Pannasch, \& Unema (2000), for example, reported that fixations around $60 \mathrm{~ms}$ made up around $7 \%$ of all fixations during a simulated driving task. Short fixations in a driving task have been also reported by Sodhi et al. (2002), who found a modal value for on-road fixation duration of $20 \mathrm{~ms}$, and a modal interval for off-road fixations of 40-60 ms. Lantieri et al. (2015) and Costa, Bonetti, et al. (2018), Costa, Simone, et al. (2018) found that in real traffic situations, due to the high dynamical context of road driving, mean fixation duration is much lower than in other

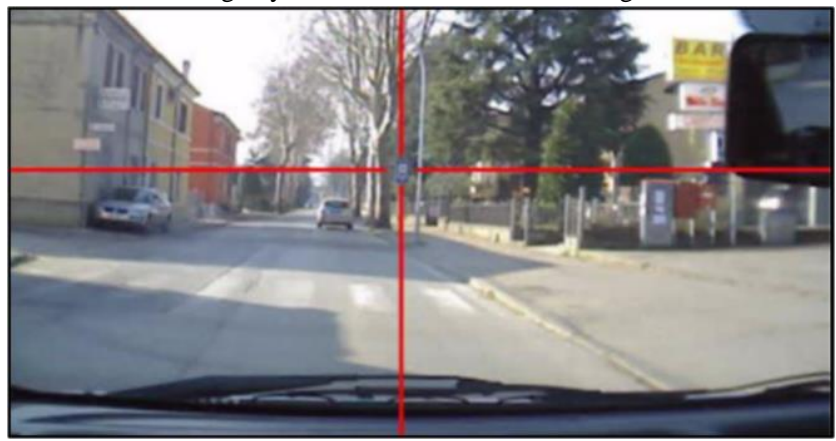

Fig. 5. Example of fixation on a traffic sign as resulting from the output of the eye-tracking mobile system.
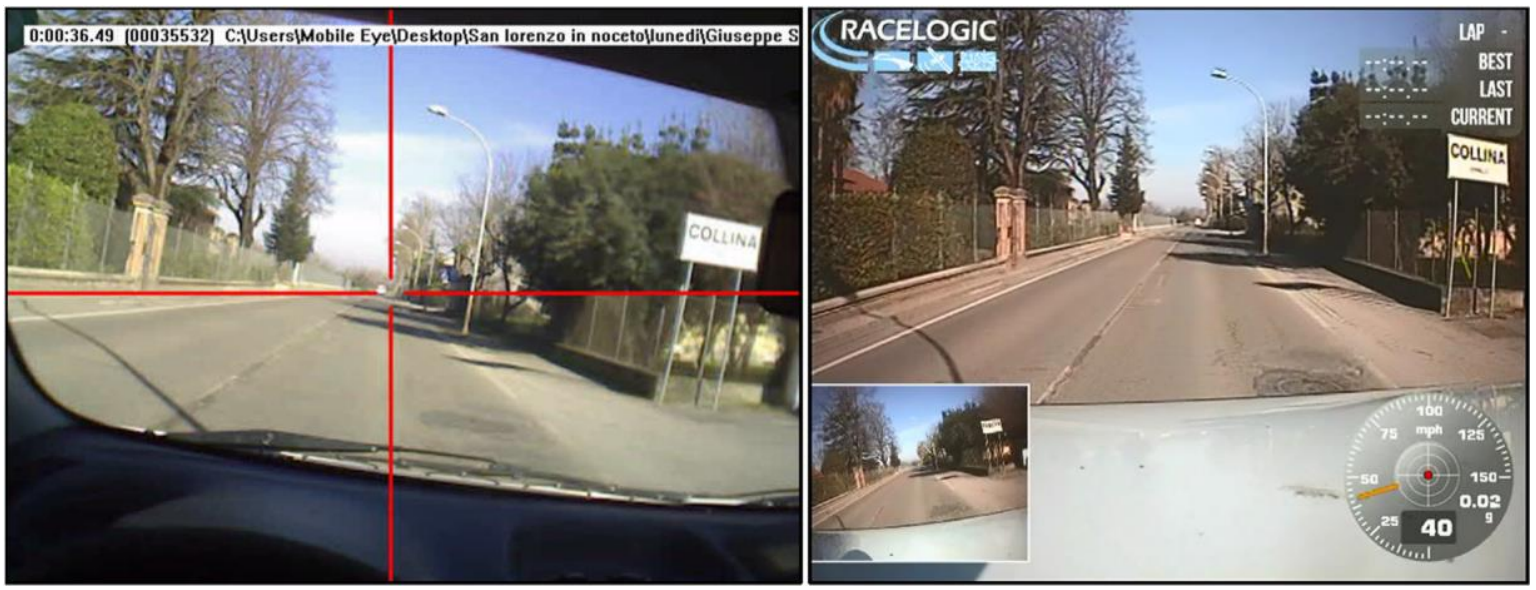

Fig. 6. Experimental setting with the synchronization of the ASL Mobile Eye-XG video output with the VBOX PRO video output.

contexts and experimental settings. In a real driving task, as in this study, car movements and the complex optical flow of the dynamical visual scene could cause very rapid fixations.

Since the distribution of fixation duration is positively skewed and not normal (Costa, Bonetti, et al., 2018; Costa, Simone, et al., 2018) medians are reported instead of means.

\subsubsection{Distance of first-fixation}

Mirroring the same methodology used in Costa, Bonetti, et al., 2018; Costa, Simone, et al., 2018 of synchronization of the speed data and the eye-tracking data, we were also able to assess the distance of first fixation for each crosswalk (Fig. 6). The distance was computed considering the driver's first fixation to any element of the crosswalk (zebra markings, vertical sign, or median refuge island). Distance of first fixation for the crosswalk was then compared to the stopping distance. The stopping distance has been evaluated using a mathematical equation in accordance with the Italian regulations (Ministry of Infrastructures and Transports, 2001). It is dependent on travelling speed (the vehicle speed at the first-fixation position), on coefficient of available friction, and on road average longitudinal slope. Considering a vehicle with an average speed equal to the speed limit $(50 \mathrm{~km} / \mathrm{h})$ and with an average road longitudinal slope of $4 \%$, as in the case under study, the stopping distance was $50 \mathrm{~m}$. 
If the first-fixation distance is longer than the stopping distance, then the driver has enough space to stop his vehicle, avoiding a conflict with pedestrians entering in the road area from the left or right side.

This comparison between the distance of first fixation and the stopping distance is very important to evaluate if the driver has enough space to stop his vehicle under safe conditions (World Road Association, 2003; Jurecki et al., 2014). All before-after analysis were performed with a univariate ANOVA.

\section{Results}

\subsection{Looking behaviour - eye movements}

In a first analysis we computed the proportion of participants that glanced at three targets: the "Yield here to pedestrians" vertical sign, the zebra crossing and, only in the after condition, the median refuge island. The results are reported in Table 1

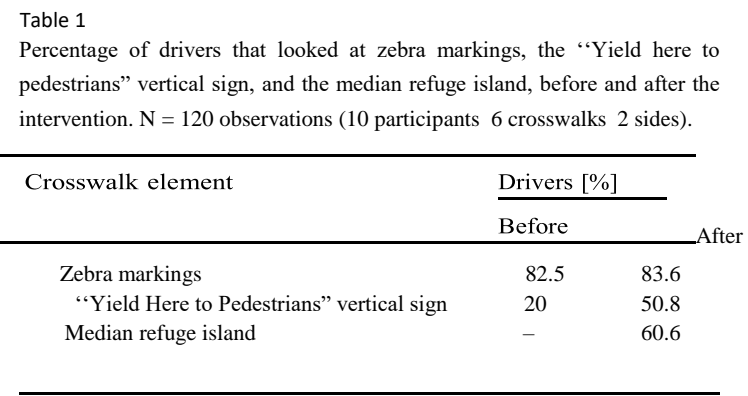

\begin{tabular}{|c|c|c|}
\hline \multirow[t]{2}{*}{ Crosswalk element } & \multicolumn{2}{|c|}{$\begin{array}{l}\text { Median fixation } \\
\text { duration [ms] }\end{array}$} \\
\hline & Before & \\
\hline \multirow[t]{2}{*}{ Zebra markings } & $433(379)$ & $900(928)$ \\
\hline & $\mathrm{N}=85$ & $\mathrm{~N}=98$ \\
\hline \multirow[t]{2}{*}{ "'Yield Here to Pedestrians" vertical sign } & $150(50)$ & $366(464)$ \\
\hline & $\mathrm{N}=24$ & $N=61$ \\
\hline \multirow[t]{2}{*}{ Median refuge island } & 1 & $366(784)$ \\
\hline & & $\mathrm{N}=72$ \\
\hline
\end{tabular}

and were based on 120 observations (10 participants 6 crosswalks 2 sides). The difference in frequencies was significant for the vertical sign ( $\mathrm{v}^{2}$ $=8.39, \mathrm{p}=.003$ ), with an increase of $30.8 \%$, whereas it was not significant for the zebra markings. The percentage of drivers that glanced at the median refuge island was $60.6 \%$ after the intervention. This feature was not part of the crosswalk design in the before-intervention condition.

Considering the fixations to the three targets, we applied two univariate ANOVAs to test the difference in mean fixation time before and after the intervention (Table 2). The difference was significant for the "Yield here to pedestrians" vertical sign: $F(1,37)=4.55, \mathrm{p}=.03, \mathrm{~g}^{2}=0.11$. Median fixation time was $150 \mathrm{~ms}(\mathrm{SD}=50)$ before the intervention and $366 \mathrm{~ms}(\mathrm{SD}=464)$ after the intervention.

The difference considering the zebra markings was also significant: $F(1,82)=10.77, \mathrm{p}=.002, \mathrm{~g}^{2}=0.11$. Median fixation time to the zebra markings was $433 \mathrm{~ms}(\mathrm{SD}=379)$ in the before condition and $900 \mathrm{~ms}(\mathrm{SD}=928)$ in the after condition. Median fixation time to the median refuge island was $366 \mathrm{~ms}(\mathrm{SD}=784)$.

\subsection{Looking behaviour - distance of first-fixation and stopping distance}

Distance of first-fixation of the crosswalks was compared before and after the intervention with an ANOVA. The mean distance was $56.49 \mathrm{~m}$ $(\mathrm{SD}=13.95, \mathrm{~N}=85)$ before the intervention and increased to $81.72 \mathrm{~m}(\mathrm{SD}=21.50, \mathrm{~N}=98)$ after the intervention. The difference was significant: $\mathrm{F}(1,87)=116.09, \mathrm{p}<.001, \mathrm{~g}^{2}=0.57$.

Distance of first-fixation for each crosswalk was compared with the corresponding stopping distance. This comparison tested if participants detected the crosswalk at a distance that could allow a safe stop in case a pedestrian entered the crossing area. The driver's behavior was classified as "unsafe" when the distance of first-fixation was lower than the stopping distance, and was considered as "safe" when the stopping distance was lower than the distance of first-fixation to the crosswalk. A cross-tabulation revealed that before the intervention $86.5 \%$ of the cases were "unsafe" 
with the stopping distance that exceeded the distance of first-fixation. After the intervention the percentage of "unsafe" cases was $31.7 \%$, with a reduction of $54.8 \%$. The difference tested with a Chi-square test was significant: $\mathrm{X}^{2}=28.17, \mathrm{p}<.001$. The comparison showed that before the interventions the drivers' first-fixation distance was not enough to stop the vehicle safely, and thatafter the installation of the median refuge island and of the "Yield here to pedestrians" flashing sign the crosswalk conspicuity increased and distance of first-fixation, allowed for a safe stop in case of pedestrians.

The influence of operating speed on first-fixation distance was tested with a linear regression. Speed was entered as independent variable and distance as dependent variable. The regression was significant: $t=2.005, \mathrm{p}<0.001, \mathrm{R}^{2}=0.061$. The standardized coefficient between the two variables was $b=0.19$, meaning that drivers tended to detect the crosswalk from a greater distance when driving at lower speeds.

For each crosswalk and for each participant, the first-fixation distance was compared with the operative stopping distance with an ANOVA. Mean stopping distance before the intervention was $74.1 \mathrm{~m}(\mathrm{SD}=11.5)$, wheres mean stopping after the intervention was $68.3 \mathrm{~m}(\mathrm{SD}=13.2)$. The difference was significant: $\mathrm{F}(1,87)=4.81, \mathrm{p}=.03, \mathrm{~g}^{2}=0.05$.

3.3. Driving behaviour - speed results

Mean speed at the time of first fixation of the crosswalk was $58.6 \mathrm{~km} / \mathrm{h}(\mathrm{SD}=5.5, \mathrm{~N}=85)$ before the intervention, and $55.6 \mathrm{~km} / \mathrm{h}(\mathrm{SD}=6.8, \mathrm{~N}=98)$ after the intervention, with a reduction of $3 \mathrm{~km} / \mathrm{h}$. The difference was significant: $\mathrm{F}(1,95)=5.21, \mathrm{p}=.02, \mathrm{~g}^{2}=0.05$. V85 changed from $65.8 \mathrm{~km} / \mathrm{h}$ to $63.3 \mathrm{~km} / \mathrm{h}$.

Average speed of participants when entering the crosswalk ( 0 -m distance condition) was $56.9 \mathrm{~km} / \mathrm{h}(\mathrm{SD}=7.7, \mathrm{~N}=85)$ before the intervention and $54.9 \mathrm{~km} / \mathrm{h}(\mathrm{SD}=6.9, \mathrm{~N}=98)$ after the intervention, with a reduction of $2 \mathrm{~km} / \mathrm{h}$. The difference, tested with an ANOVA was significant: $\mathrm{F}(1$, $198)=3.74, \mathrm{p}=.05, \mathrm{~g}^{2}=0.02$, although the effect size was rather small. V85 was in mean $64.1 \mathrm{~km} / \mathrm{h}$ before the intervention and $62.3 \mathrm{~km} / \mathrm{h}$ after the intervention.

\section{Discussion}

In this study we have assessed the impact of different safety engineering countermeasures for increasing the conspicuity of unsignalized pedestrian crossings. Specifically, we have tested the effects of an intervention that included the installation of a median refuge island and a "Yield here to pedestrians" vertical sign with flashing lights.

The evaluation was performed in a real road experimental setting, by a before-after analysis of both speed and visual behaviour of the driver's approaching to crosswalks.

We analyzed approaching speed, the speed at the time of first-fixation, and ocular fixations to the different elements of the crosswalks. In this way it was possible to understand which elements of the pedestrian crossing were more salient, and how visual behaviour was related to speed.

The concordance across the different measures contributed to confirm the positive effect of the intervention in terms of increased conspicuity and safety of the crosswalks. The median refuge island probably induced a perceptual reduction of the road width, facilitating the drivers to slow more after the intervention.

The intervention induced an increase of drivers' fixations to the crosswalk elements that captured the drivers' attention being perceptually more salient, with an increase of drivers' visual attention to the roadway, and a decrease of their distraction. Without these countermeasures, participants tended to look away from the roadway, gazing in a higher proportion the surrounding road environment. It was found a large effect of visual distraction on responses in a lead vehicle braking scenario, and also on detection of less urgent events such as a pedestrian in a crossing area (Greenberg, Tijerina, Curry, Artz, Cathey, \& Kochar, 2003; Lee, McGehee, Brown, \& Reyes, 2002).

The elements that were most seen by participants were the zebra markings, followed by the median refuge island and the "Yield here to pedestrians" flashing vertical sign. One possible explanation of this lower occurrence is that the vertical signs are not easily detected because they are set at an angle from the ahead line of sight of the driver, and therefore they fall outside of the foveal visual field of the driver, requiring specific saccadic movements or the processing in peripheral vision to be seen (Costa, Bonetti, et al., 2018; Costa, Simone, et al., 2018). The angular distance increases with poor visibility, since the sign is seen at a shorter distance.

Zebra crossings and median refuge island are placed on the plane directly in front of the drivers and are more effective in influencing drivers' behaviour, considering that drivers fix their eyes mostly on the centre of the road. This was confirmed also by Costa et al. (2014) and by Yuan, Fu, Ma, and Guo (2011), who found that the percentage of drivers' eye-fixations on the centre of the road exceeded $60 \%$, mainly on areas to the left and close to the front of the vehicle.

Therefore, to enhance the conspicuity of a crosswalk, it would be preferable to place the signs in front of the driver in an elevated position, facilitating its foveal vision (Costa, Bonetti, et al., 2018; Costa, Simone, et al., 2018; Lantieri et al., 2015).

Moreover, the intervention induced an increase of the mean distance of first-fixation to elements of the crosswalk, because drivers detected the crosswalks in advance. Their available sight distance increased with a great advantage in terms of hazard anticipation and hazard detection.

Before the intervention, drivers looked the crosswalk at a very low distance $(56.49 \mathrm{~m})$ and therefore they did not have enough time to adjust and slow down their velocity. In the after configuration drivers looked the pedestrian crossings from a longer distance $(81.72 \mathrm{~m})$, and they continued to fixate the crosswalks during their approach, maintaining an enhanced visual attention to them.

Drivers tended to detect the crosswalks from a greater distance when going at lower speeds. This is probably explained considering that at low speed the driver tends to visually explore and monitor the road more than in a condition of high speed, better detecting critical elements of the visual scene placed ahead. 
The outcomes of our study highlighted that unsignalized pedestrian crossings could strongly benefit of a design that includes a median refuge island and a "Yield here to pedestrians" flashing vertical sign. These elements are effective countermeasures in order to improve pedestrian crossing conspicuity and safety.

The results showed that the analysis of drivers' eye movements could be a very useful tool for the assessment of the conspicuity of pedestrian crossings, and for the assessment of driver behaviours, obtaining data that could guide and optimize the crosswalk design in a perspective of accident prevention.

The results of this study have a higher external validity since they were obtained in a real setting. This study was performed on a relatively small sample and future studies could test the effects of a similar intervention on a large sample. Nevertheless, we recorded significant variations of the drivers' behaviour after the intervention that were particularly remarkable in terms of visibility of the crosswalk elements, and distance of first-fixation of the crosswalks. Future studies should also test drivers' behaviour when a pedestrian is actually crossing or is in the crosswalk area.

\section{Acknowledgments}

This work was supported by the Province of Forlì-Cesena and by the "Alma Idea 2017 Costa" grant from the University of Bologna. The authors thank Luca Gardelli for his considerable help and support in this study.

\section{References}

Antov, D., Rõivas, T., Pashkevich, M., \& Ernits, E. (2013). Safety assessment of pedestrian crossings. WIT Transactions on State of the Art in Science and Engineering, 74, 41-53. https://doi.org/10.2495/978-1-84564-847-3/005.

Beeber, J. (2011). Maximizing safety at signalized intersections through increased yellow and all-red signal phases. Los Angeles: Safer Streets.

Bella, F., \& Silvestri, M. (2015). Effects of safety measures on driver's speed behaviour at pedestrian crossings. Accident Analysis and Prevention, 83, 111-124. https://doi.org/10.1016/j.aap.2015.07.016.

Biassoni, M., Confalonieri, F., \& Ciceri, R. (2018). Visual exploration of pedestrian crossings by adults and children: Comparison of strategies. Transportation Research Part F, 56, 227-235. https://doi.org/10.1016/j.trf.2018.04.009.

Bucchi, A., Sangiorgi, C., \& Vignali, V. (2012). Traffic psychology and driver behaviour. Procedia - Social and Behavioural Sciences, 53, 973-980. https://doi.org/ 10.1016/j.sbspro.2012.09.946.

Bock, O., Brustio, P. R., \& Borisova, S. (2015). Age-related differences of the gaze pattern in a realistic pedestrian traffic task. International Journal of Applied Psychology, 5, 1319. https://doi.org/10.5923/j.ijap.20150501.03.

Bongiorno, N., Bosurgi, G., Pellegrino, O., \& Sollazzo, G. (2017). How is the driver's workload influenced by the road environment? Procedia Engineering, 187, 5-13. https://doi.org/10.1016/j.proeng.2017.04.343.

Chapman, P., \& Underwood, G. (1998). Visual search of driving situations: danger and experience. Perception, 27, 951-964. https://doi.org/10.1068/p270951.

Ciceri, M., Ruscio, D., Confalonieri, F., Vangi, D., Virga, A. (2013). Hazard detection in driving context and braking reaction time. In Proceedings of the 22nd EVU annual congress. Florence, 17-19 October.

Colonna, P., Intini, P., Berloco, N., \& Ranieri, V. (2018). Integrated American-European protocol for safety interventions on existing two-lane rural roads. European Transport Research Review, 10, 1-21. https://doi.org/10.1007/s12544-017-0274-4.

Costa, M., Bonetti, L., Bellelli, M., Lantieri, C., Vignali, V., \& Simone, A. (2017). Reflective tape applied to bicycle frame and conspicuity enhancement at night. Human Factors, 59, 485-500. https://doi.org/10.1177/0018720816677145.

Costa, M., Bonetti, L., Vignali, V., Lantieri, C., \& Simone, A. (2018). The role of peripheral vision in vertical road sign identification and discrimination. Ergonomics. https://doi.org/10.1080/00140139.2018.1508756.

Costa, M., Simone, A., Vignali, V., Lantieri, C., Bucchi, A., \& Dondi, G. (2014). Looking behaviour for vertical road signs. Transportation Research Part F, 23 , 147-155. https://doi.org/10.1016/j.trf.2014.01.003.

Costa, M., Simone, A., Vignali, V., Lantieri, C., \& Palena, N. (2018). Fixation distance and fixation duration to vertical road signs. Applied Ergonomics, 69, 48-57. https://doi.org/10.1016/j.apergo.2017.12.017.

Crundall, D., \& Underwood, G. (2011). Visual attention while driving. In B. E. Porter (Ed.), Handbook of traffic psychology (pp. 137-148). London: Academic Press.

Damsere-Derry, J., Ebel, B. E., Mock, C. M., Afukaar, F., \& Donkor, P. (2010). Pedestrians' injury patterns in Ghana. Accident Analysis and Prevention, 42, 1080-1088. https://doi.org/10.1016/j.aap.2009.12.016.

Davoudian, N., \& Raynham, P. (2012). What do pedestrians look at night? Lighting, Research \& Technology, 44, 438-448. https://doi.org/10.1177/ 1477153512437157.

Dondi, G., Simone, A., Lantieri, C., \& Vignali, V. (2011). Bike lane design: The context sensitive approach. Procedia Engineering, 21, 897-906. https://doi.org/ 10.1016/j.proeng.2011.11.2092.

Dukic, T., Ahlstrom, C., Patten, C., Kettwich, C., \& Kircher, K. (2013). Effects of electronic billboards on driver distraction. Traffic Injury Prevention, 14(5), 469-476. https://doi.org/10.1080/15389588.2012.731546.

Duperrex, O., Bunn, F., \& Roberts, I. (2002). Safety education of pedestrians for injury prevention: A systematic review of randomized controlled trials. British Medical Journal, 324, 1129-1133. https://doi.org/10.1136/bmj.324.7346.1129.

Edquist, J., Rudin-Brown, C., \& Lenné, M. (2012). The effects of on-street parking and road environment visual complexity on travel speed and reaction time. Accident Analysis and Prevention, 45, 759-765. https://doi.org/10.1016/j.aap.2011.10.001.

Elvik, R., \& Vaa, T. (2004). The handbook of road safety measures. Emerald: Bingley.

Fildes, B.N., Fletcher, M.R., Corrigan, J.M, 1987. Speed perception: Drivers' judgements of safety and speed on urban and rural straight roads. Report CR 54. Department of Transport \& Communication. Canberra, Australia.

Fisher, D., \& Garay-Vega, L. (2012). Advance yield markings and drivers' performance in response to multiple-threat scenarios at mid-block crosswalks. Accident Analysis and Prevention, 44, 35-41. https://doi.org/10.1016/j.aap.2010.11.030.

Fitzpatrick, K., Turner, S.M., Brewer, M., Carlson, P.J., Ullman, B., Trout, N.D., Park, E.S., Whitacre, J., Lalani, N., Lord, D., 2006. Improving pedestrian safety at unsignalized crossings. NCHRP Report 562, Transportation Research Board, Washington.

Fotios, S., Uttley, J., Hara, N. 2013. Critical pedestrian tasks: Using eye-tracking within a dual task paradigm. In Proceedings of the CIE centenary conference “'Towards a New Century of Light". Paris, 15-16 April.

Gadiel, G. (2014). An analysis of the safety effects of crosswalks with in-pavement warning lights Master thesis. University of Massachusetts Amherst.

Gómez, R. A., Siby, S., Romoser, M. R. E., Gerardino, L. R., Knodler, M., Collura, J., \& Fisher, D. L. (2013). Proceedings of the 16th Road Safety on Four Continents Conference, Beijing.

Greenberg, J., Tijerina, L., Curry, R., Artz, B., Cathey, L., \& Kochar, D. (2003). Driver distraction evaluation with an event detection paradigm. Transportation Research Record, 1843, 1-9. https://doi.org/10.3141/1843-01.

Greibe, P. (2003). Accident prediction models for urban roads. Accident Analysis and Prevention, 35, 273-285. 
Grüner, M., \& Ansorge, U. (2017). Mobile eye tracking during real-world night driving. Journal of Eye Movement Research, 10(2), 1-18 https://doi.org/10. 16910/jemr.10.2.1.

Guo, H., Wang, W., Guo, W., Jiang, X., \& Bubb, H. (2012). Reliability analysis of pedestrian safety crossing in urban traffic environment. Safety Science, 50, 968-973. https://doi.org/10.1016/j.ssci.2011.12.027.

Guo, Y., Liu, P., Liang, Q., \& Wang, W. (2016). Effects of parallelogram-shaped pavement markings on vehicle speed and safety of pedestrian crosswalks on urban roads in China. Accident Analysis and Prevention, 95, 438-447. https://doi.org/10.1016/j.aap.2015.07.001.

Hakkert, A. S., Gitelman, V., \& Ben-Shabat, E. (2002). An evaluation of crosswalk warning systems: Effects on pedestrian and vehicle behaviour. Transportation Research Part F, 5, 275-292. https://doi.org/10.1016/S1369-8478(02)00033-5.

Hakkert, A.S., Gitelman, V., Ben-Shabat, E. (2001). An evaluation of crosswalk warning systems. In Proceedings of the Transportation Research Board 80 annual meeting, Washington, D.C.

Haleem, K., Alluri, P., \& Gan, A. (2015). Analysing pedestrian crash injury severity at signalized and non-signalized locations. Accident Analysis and Prevention, 81, 14-23.

Hamed, M. M. (2001). Analysis of pedestrians' behaviour at pedestrian crossings. Safety Science, 38, 63-82. https://doi.org/10.1016/S0925-7535(00)00058-8.

Hawley, L., Henson, C., Hulse, A., Brindle, R., 1992. Towards traffic calming: a practitioners' manual of implemented local area traffic management and blackspot devices. Publication No. CR 126. Federal Office of Road Safety. Canberra, Australia.

Holmqvist, K., Nystrom, M., Andersson, R., Dewhurst, R., Jarodzka, H., \& van De Weijer, J. (2015). Eye tracking: A comprehensive guide to methods and measures. Oxford: Oxford University Press.

Horswill, M. S., \& McKenna, F. P. (2004). Drivers' hazard perception ability: Situation awareness on the road. In S. Banbury \& S. Tremblay (Eds.), A cognitive approach to situation awareness. Aldershot, UK: Ashgate.

Huang, H., Cynecki, M., 2001. The effects of traffic calming measures on pedestrian and motorist behavior. Federal Highway Administration, FHWA-RD-00104.

Inman, V. W., 2012. Conspicuity of traffic signs assessed by eye tracking and immediate recall. In Proceedings of the human factors and ergonomics society, 56th annual meeting, p. 2251-2255.

Jurecki, R. S., \& Stanczyk, T. L. (2014). Driver reaction time to lateral entering pedestrian in a simulated crash traffic situation. Transportation Research Part F, 27, 22-36. https://doi.org/10.1016/j.trf.2014.08.006.

Kannel, E. J., \& Jansen, W. (2004). In-pavement pedestrian flasher evaluation. Report No. CTRE Project 03-145. Center for Transportation Research and Education, Iowa State University.

Kapitaniak, B., Walczak, M., Kosobudzki, M., Józ'wiak, Z., \& Bortkiewicz, A. (2015). Application of eye tracking in drivers testing: A review of research. International Journal of Occupational Medicine and Environmental Health, 28, 941-954 https://doi.org/10.13075/ijomeh.1896.00317.

Kim, K., Made Brunner, I., \& Yamashita, E. (2012). Characterization of pedestrian accidents and an examination of infrastructure measures to improve pedestrian safety in Israel. Accident Analysis and Prevention, 44, 63-73. https://doi.org/10.1016/j.aap.2010.11.017.

Klauer, S. G., Dingus, T. A., Neale, V. L., Sudweeks, J. D., \& Ramsey, D. J. (2006). The impact of driver inattention on near-crash/crash risk: An analysis using the 100-car naturalistic driving study data. DOT HS 810 594. NHTSA, U.S. Department of Transportation.

Kolsrud, B., 1985. Speeds in rural traffic: The influence of various factors on car speeds on straight level roads. VTI Meddelande 390, Sweden.

Kröyer, H. R. G., Jonsson, T., \& Várhelyi, A. (2014). Relative fatality risk curve to describe the effect of change in the impact speed on fatality risk of pedestrians struck by a motor vehicle. Accident Analysis and Prevention, 62, 143-152. https://doi.org/10.1016/j.aap.2013.09.007.

Land, M., \& Tatler, B. (2009). Vision and eye movements in natural behaviour. Visual Neuroscience, 26, 51-62. https://doi.org/10.1017/S0952523808080899.

Lantieri, C., Lamperti, R., Simone, A., Costa, M., Vignali, V., Sangiorgi, C., \& Dondi, G. (2015). Gateway design assessment in the transition from high to low speed areas. Transportation Research Part F, 34, 41-53. https://doi.org/10.1016/j.trf.2015.07.017.

Leden, L., Gårder, P., \& Johansson, C. (2006). Safe pedestrian crossings for children and elderly. Accident Analysis and Prevention, 38, 289-294. https://doi.org/ 10.1016/j.aap.2005.09.012.

Lee, J. D., McGehee, D. V., Brown, T., \& Reyes, M. L. (2002). Collision warning, driver distraction, and driver response to rear-end collisions in a high-fidelity driving simulator. Human Factors, 44, 314-334. https://doi.org/10.1518/0018720024497844.

Macbeth, A., 1995. Balliol Street, City of Toronto. Traffic engineering committee workshop. In Proceedings of the Ontario traffic conference, Toronto, Ontario, Canada.

Malek, M., 2001. Crosswalk enhancement comparison study. In Proceedings of the institute of transportation engineers 2001 annual meeting and exhibit, Chicago.

Mantuano, A., Bernardi, S., \& Rupi, F. (2017). Cyclist gaze behavior in urban space: An eye-tracking experiment on the bicycle network of Bologna. Case Studies on Transport Policy, 5, 408-416. https://doi.org/10.1016/j.cstp.2016.06.001.

Malek, M., 2001. Crosswalk enhancement comparison study. In Proceedings of the institute of transportation engineers 2001 annual meeting and exhibit, Chicago.

Maxera, P., Kledus, R., Semela, M., 2015. Analysis of drivers' conduct while driving over pedestrian crossing by using eye-tracking method. In Proceedings of the international scientific conference modern safety technologies in transportation. Košice, Slovakia.

Ministry of Infrastructures and Transports, 1992. Codice della strada [Highway code]. Rome (in Italian).

Ministry of Infrastructures and Transports, 2001. Decreto Ministeriale del 5/11/2001 Norme funzionali e geometriche per la costruzione delle strade. Rome (in Italian).

O’Neill, B., Mohan, D., Breen, J., Koonstra, M. J., Mackay, M., Roberts, I., \& Ryan, G. A. (2002). Commentary on the world bank's global road safety partnership. Traffic Injury Prevention, 3, 190-194.

Olson, P. L., Battle, D. S., Aoki, T., 1989. Driver eye fixations under different operating conditions. Final Report No. UMTRI-89-3. Minneapolis.

Olszewski, P., Szagała, P., Wolanski, M., \& Zielinska, A. (2015). Pedestrian fatality risk in accidents at unsignalized zebra crosswalks in Poland. Accident Analysis and Prevention, 84, 83-91. https://doi.org/10.1016/j.aap.2015.08.008.

Pasanen, E. (1992). Driving speeds and pedestrian safety: a mathematical model. Helsinki University of Technology, Transport Engineering, Publication 77.

Pomarjanschi, L., Dorr, M., \& Barth, M. (2012). Gaze guidance reduces the number of collisions with pedestrians in a driving simulator. ACM Transactions on Interactive Intelligent Systems, 1, 1-14. https://doi.org/10.1145/2070719.2070721.

Pulugurtha, S. S., Krishnakumar, V. K., \& Nambisan, S. S. (2007). New methods to identify and rank high pedestrian crash zones: An illustration. Accident Analysis and Prevention, 39, 800-811. https://doi.org/10.1016/j.aap.2006.12.001.

Randal, J. (2005). Pedestrian safety impacts of curb extensions: A case study. Corvallis: Oregon State University.

Replogle, M., 1992. Bicycle and pedestrian policies and programs in Asia, Australia, and New Zealand: Case Study 17. National Bicycling and Walking Study. Report No. FHWAPD-93-016. Federal Highway Administration. Washington, DC.

Retting, R. A., Fergusson, S. A., \& McCartt, A. T. (2003). A review of evidence-based traffic engineering measures designed to reduce pedestrian-motor vehicle crashes. American Journal of Public Health, 93, 9.

Rosén, E., \& Sander, U. (2009). Pedestrian fatality risk as a function of car impact speed. Accident Analysis and Prevention, 41, 536-542.

Rosén, E., Stigson, H., \& Sander, U. (2011). Literature review of pedestrian fatality risk as a function of car impact speed. Accident Analysis and Prevention, 43, $25-33$.

Rousseau, G., Tucker, S.M., Do, A., 2004. The effects on safety of in-roadway warning lights at crosswalks: Novelty or longevity? Proceedings of the Institute of Transportation Engineers 2004 Annual Meeting and Exhibit, Lake Buena Vista.

Samuel, S., Romoser, M., Gerardino, L., Hamid, M., Gómez, R., Knodler, M., ... Fisher, D. (2013). Effect of advance yield markings and symbolic signs on vehicle-pedestrian conflicts: Field evaluation. Transportation Research Record, 2393, 139-146 https://doi.org/10.3141\%2F2393-16.

Sanca, M. (2002). Application of design for safer urban roads and junctions: Selected countermeasures. Sweden: Linkoping University.

Sherbutt, J., Van Houten, R., Turner, S., \& Huitema, B. (2009). Analysis of effects of LED rectangular rapid-flash beacons on yielding to pedestrians in multilane crosswalks. Transportation Research Record, 2140, 85-95. https://doi.org/10.3141/2140-09.

Sisopiku, V. P., \& Akin, D. (2003). Pedestrian behaviours at and perceptions towards various pedestrian facilities: An examination based on observation and survey data. Transportation Research Part F, 6, 249-274. https://doi.org/10.1016/j.trf.2003.06.001. 
Sodhi, M., Reimer, B., Cohen, J. L., Vastenburg, E., Kaars, R., Kirschenbaum, S., 2002. On-road driver eye movement tracking using head-mounted devices. In Proceedings of the 2002 symposium on eye tracking research \& applications. pp. 61-68.

Taylor, T., Pradhan, A. K., Divekar, G., Romoser, M., Muttart, J., Gomez, R., Pollatsek, A., \& Fisher, D. L. (2013). The view from the road: The contribution of onroad glancemonitoring technologies to understanding driver behavior. Accident Analysis and Prevention, 58, 175-186. https://doi.org/10.1016/j. aap.2013.02.008.

Tefft, B. C. (2013). Impact speed and a pedestrian's risk of severe injury or death. Accident Analysis and Prevention, 50, 871-878. https://doi.org/10.1016/j. aap.2012.07.022.

Topolšek, D., Areh, I., \& Cvahte, T. (2016). Examination of driver detection of roadside traffic signs and advertisements using eye tracking. Transportation Research Part F: Traffic Psychology and Behaviour, 43, 212-224. https://doi.org/10.1016/j.trf.2016.10.002.

Trefzger, M., Blascheck, T., Raschke, M., Hausmann, S., Schlegel, T., 2018. A visual comparison of gaze behavior from pedestrians and cyclists. In Symposium on eye tracking research and applications, Warsaw, Poland.

Van Houten, R., Ellis, R., \& Marmolejo, E. (2008). Stutter-flash light-emitting-diode beacons to increase yielding to pedestrians at crosswalks. Transportation Research Record, 2073, 69-78. https://doi.org/10.3141/2073-08.

Van Houten, R., Malenfant, J. E. L., \& McCusker, D. (2001). Advance yield markings reduce motor vehicle/pedestrian conflicts at multilane crosswalks with an uncontrolled approach. Transportation Research Record, 1773, 69-74. https://doi.org/10.3141/1773-08.

Van Houten, R., McCusker, D., Huybers, S., Malenfant, J. E. L., \& Rice-Smith, D. (2002). Advance yield markings and fluorescent yellow-green RA-4 signs at crosswalks with uncontrolled approaches. Transportation Research Record, 1818, 119-124. https://doi.org/10.3141/1818-18.

Várhelyi, A. (1998). Drivers' speed behaviour at a zebra crossing: A case study. Accident Analysis and Prevention, 30, 731-743. https://doi.org/10.1016/S00014575(98)00026-8.

Velichkovsky, B., Domhoefer, S.M., Pannasch, S., Unema, J.A., 2000. Visual fixations and level of attentional processing. In Proceedings of the eye tracking research \& application symposium, ETRA 2000, Palm Beach Gardens, Florida, 6-8 November.

Vey, A. H., \& Ferreri, M. G. (1968). The effect of lane width on traffic operation. Traffic Engineering, 38, $22-27$.

World Road Association (PIARC), 2003. Road safety manual.

Yagar, S., \& Van Aerde, M. (1983). Geometric and environmental effects on speeds on 2-lane rural roads. Transportation Research Record, 17A, 315.

Yuan, W., Fu, R., Ma, Y., \& Guo, Y. S. (2011). Effects of vehicle speed and traffic sign text height on drivers' visual search patterns. Journal of Traffic and Transportation Engineering, 11, 119-126.

Zeeger, C. V., \& Bushell, M. (2012). Pedestrian crash trends and potential countermeasures from around the world. Accident Analysis and Prevention, 44, 3-11. https://doi.org/10.1016/j.aap.2010.12.007.

Zito, G. A., Cazzoli, D., Scheffler, L., Jäger, M., Müri, R. M., Mosimann, U. P., ... Nef, T. (2015). Street crossing behavior in younger and older pedestrians: An eyeand headtracking study. BMC Geriatrics, 15, 176. https://doi.org/10.1186/s12877-015-0175-0. 